\title{
Bonding of all Ceramic Restorations
}

\author{
Nissaf Daouahi*, Dalenda Hadyaoui and Mounir Cherif
}

Department of Fixed Prosthodontics, Faculty of Dentistry, University of Monastir, Monastir, Tunisia

\begin{abstract}
The use of all-ceramic crowns offers the potential for improved aesthetic results compared to conventional ceramometal crowns. Silica/glass-based all-ceramic crowns are more translucent than alumina or zirconia-based crowns and therefore have better optical properties. However, they are mechanically weaker and need to be used in conjunction with resin bonding cements. It is accepted that adhesion between ceramics and resin cements is provided by two major mechanisms namely micromechanical attachment and chemical bonding. Due to its resistance to aggressive chemical agents, chemical bonding of zirconia is difficult when compared to silica-based ceramics materials.

In this paper, we discuss the luting modalities of both glass ceramics and zirconia based ceramics through a clinical report. It describes a case of rehabilitation of a missing lateral incisor and a peg lateral incisor using zirconia Cantilever Bridge and a ceramic veneer. Depending on material properties, the zirconia based restoration was mechanically bonded meanwhile the ceramic veneer was chemically bonded. The final result was esthetically acceptable and the patient was satisfied.
\end{abstract}

Keywords: Ceramics; Bonding; Cementation; Glass ceramic materials; Zirconia

\section{Introduction}

All clinicians are in general agreement that, the success of nonmetallic restoration primarily depends on the luting agent. In fact, it guarantees an effective and durable adhesion with the dental structure [1]. Nowadays, there are increasing cases where retention and strength of the restoration are reliant on bonding [1-3]. Adhesive bonding systems are introduced in dental practice not only to improve the retention but also to achieve better aesthetic results and maintain high ceramic strength. According to recent studies, bonded all-ceramic restorations show a higher fracture resistance than conventionally cemented restorations [4-11]. This arises from the fact that resin cement used in bonded restorations is elastic and it tends to deform under stress conducting to a higher resistance to fracture. As a consequence when selecting the bonding system, the elastic modulus of the material is of interest [12].

Based on the chemical composition especially the content of the glass phase, ceramics are generally classified into glass ceramics (silicate) and crystalline ceramics (oxide) which are also, called high strength core ceramics. Glass ceramics are characterized by a dominant glass phase. Whereas, crystalline ceramics are defined as a group of ceramics containing not more than $15 \%$ silica with little or no glass phase [13].

When the clinician deals with bonding of silica-based ceramic restoration, the material surfaces are usually etched by hydrofluoric acid with or without grit blasting for mechanical interlocking, and then silanated in order to create a topography conducting to micromechanical and chemical bonding to dental resin cements. It seems to be an easy task but it requires knowledge of adhesive principles and meticulous adherence to the clinical protocol. The application of appropriately selected adhesive material with proper technique will ensure a successful long term clinical outcome [3].

When it comes to zirconia based restorations, the chemical bonding using resin cements still questionable. In fact, it is a key problem faced using crystalline ceramic restorations and considered as a challenging task confronted by such clinicians. Contrary to silica based ceramics, its surface cannot be etched by hydro fluoric acid which is the usual chemical means to condition the surface $[14,15]$. To overcome the problem of creating micro porosity and providing adherence of resin to crystalline ceramics, some methods have been proposed and advocated in the literature. They include applying primers containing acidic methacrylates, laser irradiation and deposing reactive silicate layers on the zirconia surface.

Successful adhesion depends on proper cleaning of the internal surface of the restoration conducting to a strong link between the cement and the restoration [3]. According to recent studies, analysis of results leads to the fact that surface treatments of ceramics, mechanical or chemical, have an important influence on adhesion strength for both Zirconia based ceramics and glass ceramics $[3,16]$. But, it is also very important to remember that Zirconia crowns can also be cemented with conventional cements if adequate crowns preparation design provides sufficient retention without bonding [14].

\section{Case Report}

A 22 year old female patient was referred to the Department of Prosthodontics at Monastir University. She had unilateral congenitally missing lateral incisor. Her medical history was non relevant while the dental history revealed that an orthodontic treatment was set up with a space opening leading to a correct spacing for the left missing lateral incisor. The patient was wearing ESSIX appliances and was looking for a symmetrical aspect and a pleasing full smile (Figure 1). She was requiring a minimally invasive approach as possible.

Intra oral examination showed a peg lateral incisor in the right side which can complicate the treatment and compromises the symmetrical final aspect. Soft tissues were healthy and oral hygiene was evaluated as good. The edentulous ridge was measured and it was suitable for adequate dimensions of lateral incisor. The adjacent teeth were vital,

*Corresponding author: Nissaf Daouahi, Doctor of Dental Medicine, Department of Fixed Prosthodontics, Faculty of Dentistry, University of Monastir, Monastir Tunisia 5000, Tunisia, Tel: +216-98-676-349; E-mail: nissafdaouahi@gmail.com

Received September 08, 2015; Accepted September 24, 2015; Published October 03, 2015

Citation: Daouahi N, Hadyaoui D, Cherif M (2015) Bonding of all Ceramic Restorations. Dentistry 5: 338. doi:10.4172/2161-1122.1000338

Copyright: ( 2015 Daouahi N, et al. This is an open-access article distributed under the terms of the Creative Commons Attribution License, which permits unrestricted use, distribution, and reproduction in any medium, provided the original author and source are credited. 


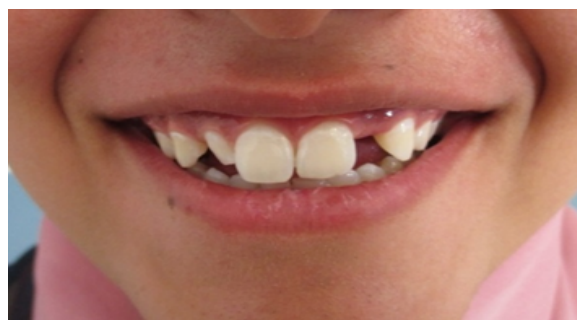

Figure 1: Initial situation showing an impaired aesthetic aspect.

free from caries and fillings with a suitable crown volume and height. Careful occlusion evaluation showed that canine guidance was lost in favor of a premolar and molar guidance. A radiographic exam had been established for a diagnosis and a treatment plan. A mock up aiming the simulation of the final shape and shade of the peg lateral incisor was performed using resin composite. Diagnostic casts were waxed to assess the treatment plan.

For the replacement of the missing lateral incisor, Tomographic Dental Scans analysis revealed that implant therapy was not suitable. In the same context, micro cracks were detected on the canine which contraindicates fixed partial restorations. So the decision of a zirconia based all ceramic resin bonded fixed partial denture was rejected. In this case, a ceramic veneer using a lithium disilicate reinforced glass ceramic was indicated to reshape the peg lateral left incisor. The decision of based zirconia cantilever bridge, in order to replace the agenetic lateral incisor, was retained. In fact, laboratory investigations of the fracture resistance of zirconia based cantilever bridge provided disappointing results. However, depending on the framework design, fracture loads were approximately between $350 \mathrm{~N}$ and $550 \mathrm{~N}$ suggesting that zirconia based cantilever bridge should not be recommended for the clinical replacement of only a missing posterior tooth.

\section{Clinical procedure}

The preparation was done using Index silicone guide in order to control the reduction and prevent over contours (Figure 2). Preparation margins were supra gingivally placed on the peg lateral incisor. Meanwhile, they were intrasulcularly placed on the canine for more retention.

A cantilever provisional bridge was, elaborated using auto polymerized resin TEXTON (SS White, Ce 0473, Prima Dental Group, England), putty index made from the wax up and cemented with temporary cement (Temp Bond Type I Class 1Ce 0086, Kerr, Italy). Temporization for the ceramic veneer was done using resin composite followed by spot etching of the prepared surface.

The full arch impression was made with a combination of heavy and light silicon (HydroC, Detax, Germany). The shade was determined with a shade guide (Vitapan 3D Master). The framework of the bridge and the ceramic veneer were manufactured using the CAD/CAM technology (Figures 3 and 4). After try in stage, the framework was veneered with a compatible porcelain system with a thickness between $1 \mathrm{~mm}$ to $2 \mathrm{~mm}$ (Figure 5). An aesthetic try in of the restorations was made before final staining and glazing. For a secure bonding, the use of rubber dam was necessary.

The treatment of ceramic surfaces starts with the etching of internal surface of the veneer with hydro fluoric acid after waxing the external surface in order to protect it from acid action (Figure 6). Silane coupling agent was then applied (Figure 7). When it comes to conditioning teeth surfaces, the prepared surfaces were first cleaned using chlorhexidine (Figure 8). The peg lateral incisor was etched for $15 \mathrm{sec}$ using $37 \%$ phosphoric acid and then rinsed off (Figure 9). Third, it was coated with bonding agent in thin layer and polymerized for $15 \mathrm{sec}$ (Figures 10

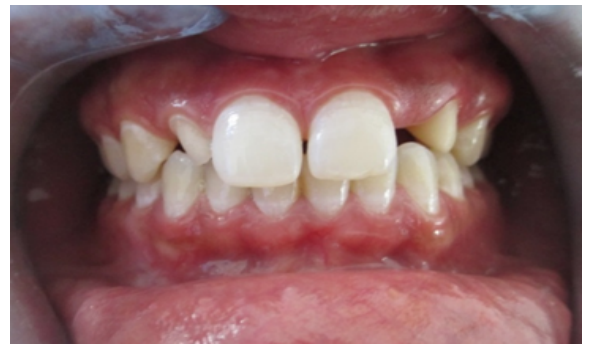

Figure 2: Preparation of abutment teeth.

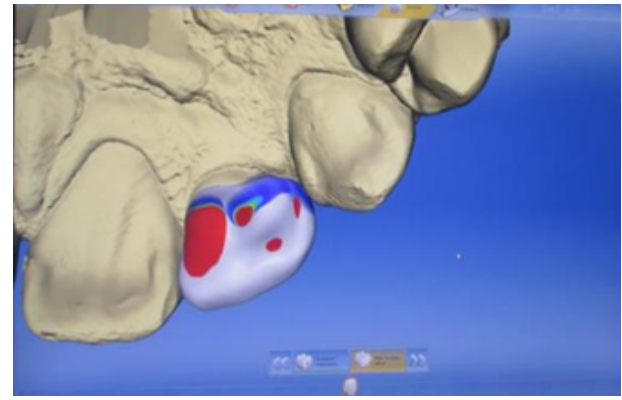

Figure 3: CAD/CAM procedure design of the ceramic veneer.

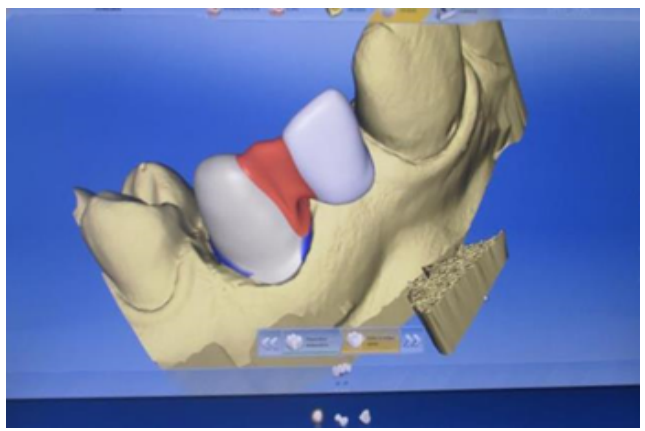

Figure 4: CAD/CAM procedure design of the cantilever bridge.

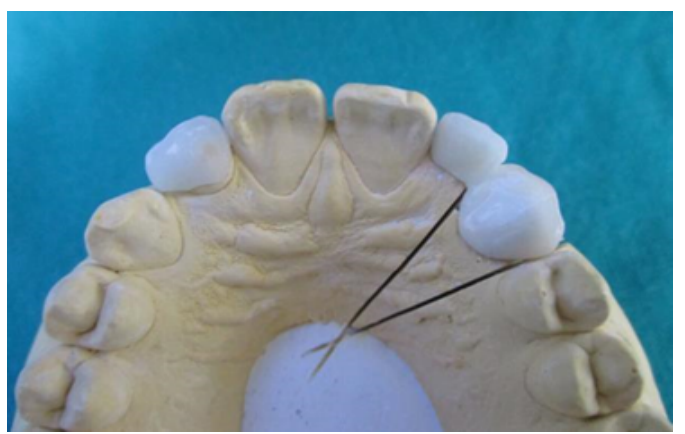

Figure 5: Final restorations. 


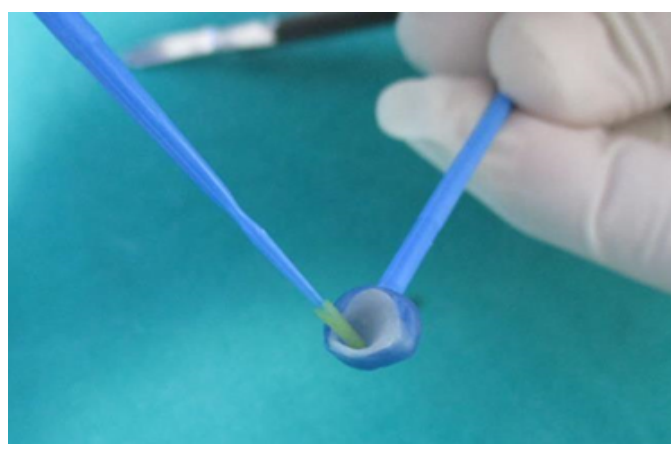

Figure 6: Etching of the ceramic veneer.

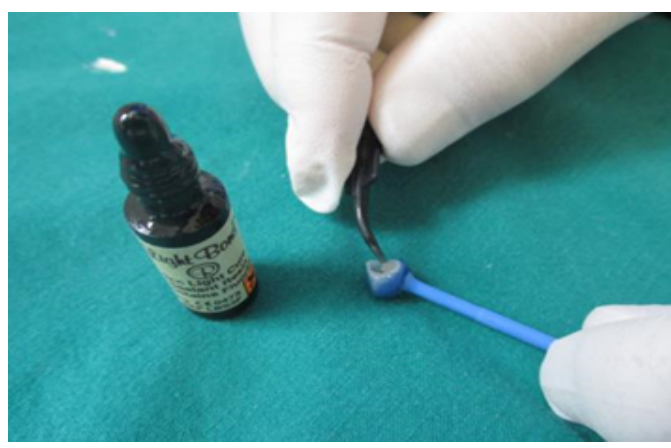

Figure 7: Application of the silane coupling agent.

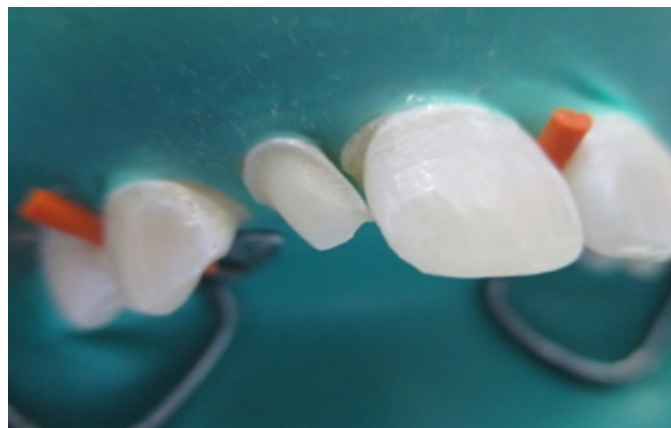

Figure 8: Rubber dam placement and surface tooth cleaning

and 11). Finally, resin luting agent is applied to the restoration and the preparation. The restoration was seated and excess luting material was removed. The restoration should be supported while the resin is cured. Gross excess resin can be removed after a spot cure. Light curing is then done in accordance with the resin manufacturer recommendations. In the same time, the internal surfaces of the bridge were abraded with $50 \mu \mathrm{m}$ aluminum oxide particles at a pressure of $1.0 \mathrm{bar}$. Reducing the pressure during air abrasion and using particles up to $50 \mu \mathrm{m}$ in size is beneficial to avoid structural defects of zirconia. A special care should be given to protect the feldspathic veneering porcelain from abrasion. The bridge was then cemented using the resin relyX Unicem ${ }^{\mathrm{R}}$.

Luting of the ceramic veneer was a chemical bonding meanwhile; it was a mechanical bonding after surface roughening for the Zirconia based bridge (Figure 12). The patient was satisfied with the result (Figure 13).

\section{Discussion}

In spite of advantages of all ceramic restorations including biocompatibility and aesthetic appearance, there are still disadvantages to their use. In fact, they are brittle which can lead to catastrophic fracture, especially in silica/glass based ceramics. In such cases, strengthening effect of adhesive luting been proved by several studies [14]. It provides additional reinforcement to both the restoration and the dental tissue. Effective adhesion achieved between the cementrestoration and cement-dentin interfaces conducts to an effective distribution of the occlusal forces along the restoration and dental structure [3]. Due to the elasticity of used resin cement, which tends to deform under stress conduction, resistance to fracture was improved.

In addition, the infiltration of resin creates a micro- mechanical

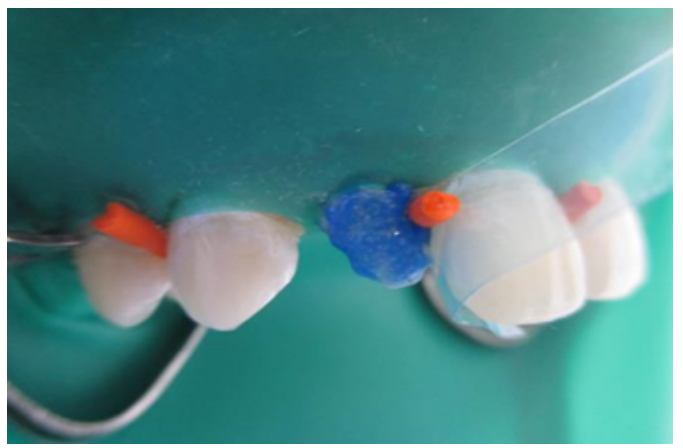

Figure 9: Treatment of the tooth surfaces: etching.

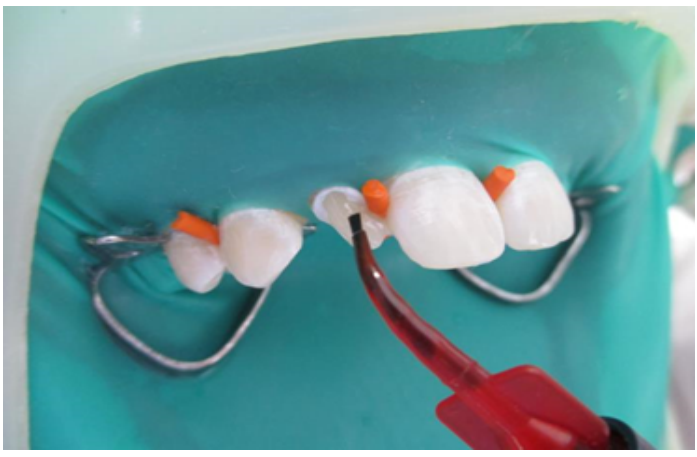

Figure 10: Application of the primer.

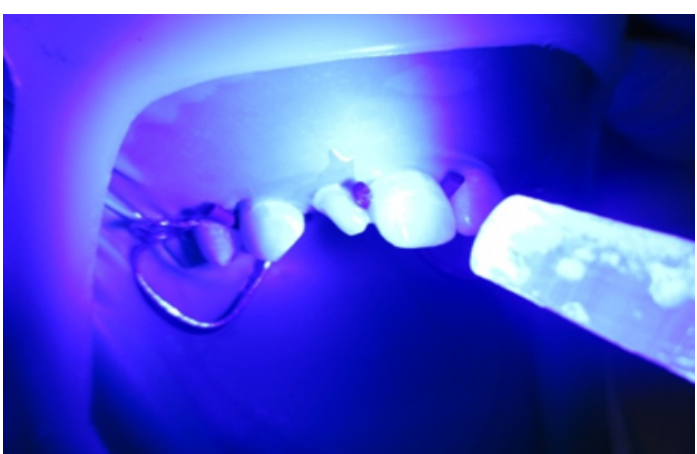

Figure 11: Photo polymerization. 


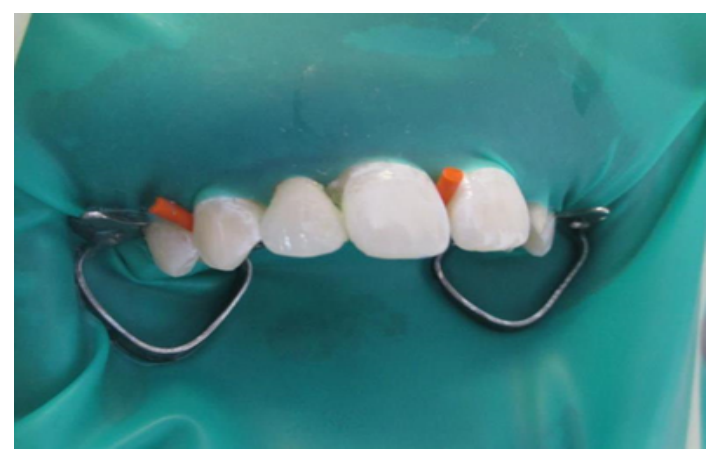

Figure 12: The restoration after chemical bonding.

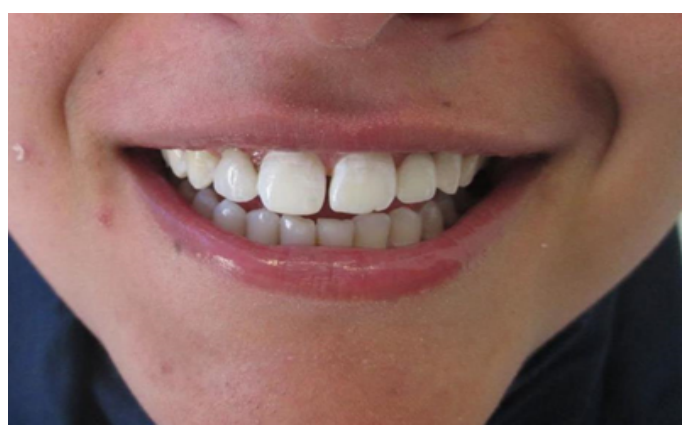

Figure 13: Final result

retention of resin tags with the demineralized substrate improving in that order, the retention of the restoration. This means that, more the tubules widened by the etchant, the greater is the chance of obtaining a reliable bond [17].

According to literature, the bond strength between the ceramic and the tooth structure is affected by tooth surface conditioning. It has been shown that, restorations bonded to teeth using the total etch technique achieved a bond strength of up to $28 \mathrm{MPa}$ [18] within the enamel and 13 to $20 \mathrm{MPa}$ within the dentin $[19,20]$. Improved bond strength to dentin can be reached when an immediate sealing of the dentin after the preparation is done [21]. It has also shown that for a secure bonding, conditioning of the enamel and dentin separately is preferred [22].

The quality of the strength bond is, in one hand strongly depends on the composition of the ceramic material and its ability to surface treatments. This fact was proved by several studies where scientists have concluded that various glass ceramic types may produce different micro structure after different surface treatments [2]. On the other hand, its effectiveness is related to the type of silane coupling agent which is bi-functional compound that promote connection between dissimilar organic and inorganic counterparts. According to authors, the concentration of the silane solution does not affect the bond strength to dental leucite-based glass ceramics [14,22-24].

Generally, hydrofluoric acid is an easy surface treatment for silicate-containing ceramics [25]. But, some oxide ceramics particularly zirconia which contains no glass phase cannot be etched using this acid [26]. In addition, the well-known methods of bonding used on glassceramics are not applicable for use with zirconia due to its chemical inertness and its resistance to aggressive chemical agents. Moreover, ordinary silane chemistry also may not improve the affinity of resin cements for zirconia $[23,24,27]$. This fact makes bonding of zirconia difficult when compared to silica-based ceramics materials [28]. In this context, some scientists suggested the application of a fused glass ceramic on the zirconia surface which is then etchable and as a consequence able to adhesive cementation.

Because of the difficulty in creating mechanical and chemical bonding in zirconia, alternative methods have been explored and surface grinding is a commonly used alternative for roughening the surface of Zirconium dioxide $\left(\mathrm{ZrO}_{2}\right.$ to ensure only mechanical bonding. These methods include grinding using abrasive paper or wheels, particle air abrasion using Aluminium oxide or other abrasive particles and grinding using diamond burs. These grinding methods are generally easy to apply in dental environment [29].

Generally, there are few in vitro studies on the long term resin bond to zirconia ceramics. Due to high fracture resistance and its composition which differs from silica based ceramics, zirconia based restorations can be cemented conventionally, as recommended by some manufacturers, thus mechanically retaining them to the teeth [30]. Moreover, in some instances high strength ceramic restorations do not require adhesive bonding to tooth structure and can be placed using conventional cements which ensure only a micro-mechanical retention. However, mechanical resin bonding is desirable in many clinical situations when the prepared tooth is unsually short [24].

\section{Conclusions}

Adhesive luting is fundamental procedure for strengthening glass ceramics and not affecting the strength of crystalline ceramics. To overcome the problem of creating microporosity and providing adherence of resin luting agents to crystalline ceramics some methods have been proposed. Due to high fracture resistance and its composition which differs from silica based ceramics, zirconia based restorations can be cemented conventionally.

\section{Acknowledgments}

The authors would like to thank colleagues from the Department of Prosthodontics, Faculty of Dentistry, University of Monastir for their support.

\section{References}

1. Sailer I, Makarov NA, Thoma DS, Zwahlen M, Pjetursson BE (2015) Allceramic or metal-ceramic tooth-supported fixed dental prostheses (FDPs)? A systematic review of the survival and complication rates. Part I: Single crowns (SCs). Dent Mater 31: 603-623.

2. Tian T, Tsoi JK, Matinlinna JP, Burrow MF (2014) Aspects of bonding between resin luting cements and glass ceramic materials. Dent Mater 30: e147-e162.

3. Santos GC Jr, Santos MJ, Rizkalla AS (2009) Adhesive cementation of etchable ceramic esthetic restorations. J Can Dent Assoc 75: 379-384.

4. Malament KA, Socransky SS (2001) Survival of Dicor glass-ceramic denta restorations over 16 years. Part III: Effect of luting agent and tooth or toothsubstitute core structure. J Prosthet Dent 86: 511-519.

5. Diaz-Arnold AM, Vargas MA, Haselton DR (1999) Current status of luting agents for fixed prosthodontics. J Prosthet Dent 81: 135-141.

6. Kao EC, Johnston WM (1991) Fracture incidence on debonding of orthodontic brackets from porcelain veneer laminates. J Prosthet Dent 66: 631-637.

7. Klosa K, Wolfart S, Lehmann F, Wenz HJ, Kern M (2009) The effect of storage conditions, contamination modes and cleaning procedures on the resin bond strength to lithium disilicate ceramic. J Adhes Dent 11: 127-135.

8. McCormick JT, Rowland W, Shillingburg HT Jr, Duncanson MG Jr (1993) Effect of luting media on the compressive strengths of two types of all-ceramic crown. Quintessence Int 24: 405-408.

9. Piwowarczyk A, Bender R, Ottl P, Lauer HC (2007) Long-term bond between 
dual-polymerizing cementing agents and human hard dental tissue. Dent Mater 23: $211-217$.

10. Scherrer SS, De Rijk WG, Belser UC (1996) Fracture resistance of human enamel and three all-ceramic crown systems on extracted teeth. Int $\mathrm{J}$ Prosthodont 9: 580-585.

11. Yoshinari M, Derand T (1994) Fracture strength of all-ceramic crowns. Int J Prosthodont 7: 329-338.

12. Saridag S, Sevimay M, Pekkan G (2013) Fracture resistance of teeth restored with all-ceramic inlays and onlays: an in vitro study. Oper Dent 38: 626-634.

13. Kern M (2009) Resin bonding to oxide ceramics for dental restorations. J Adhes Sci Technol 23: 1097-1111.

14. Oliveira-Ogliari A, Vasconcelos CS, Bruschi RC, Gonçalves AP, Ogliari FA, et al. (2014) Thermal silicatization: A new approach for bonding to Zirconia ceramics. Int J Adhes Adhes 48: 164-167.

15. Everson P, Addison O, Palin WM, Burke FJ (2012) Improved bonding of Zirconia substructures to resin using a "glaze-on" technique. J Dent 40: 347 351.

16. Doucet S, Tavernier B, Colon P, Picard B (2008) Adhesion between denta ceramic and bonding resin quantitative evaluation by Vickers indenter methodology. Dent Mater 24: 45-49.

17. Ferrari M, Cagidiaco MC, Vichi A, Mannocci F, Mason PN, et al. (2001) Bonding of all porcelain crowns: structural characteristics of the substrate. Dent Mater 17: $156-164$

18. Kern M, Thompson VP (1993) A simple method for universal testing of tensile bond strength. Dtsch Zahnärztl Z 48: 769-772.

19. Fortin D, Swift EJ Jr, Denehy GE, Reinhardt JW (1994) Bond strength and microleakage of current dentin adhesives. Dent Mater 10: 253-258.
20. Sarr M, Mine A, De Munck J, Cardoso MV, Kane AW, et al. (2010) Immediate bonding effectiveness of contemporary composite cements to dentin. Clin Oral Investig 14: 569-577.

21. Magne P (2014) IDS: Immediate Dentin Sealing (IDS) for tooth preparations. $J$ Adhes Dent 16: 594

22. Rocca GT, Krejci I (2007) Bonded indirect restorations for posterior teeth: From cavity preparation to provisionalization. Quintessence Int 38: 371-379.

23. Hooshmand T, Matinlinna JP, Keshvad A, Eskandarion S, Zamani F (2013) Bond strength of a dental leucite-based glass ceramic to a resin cement using different silane coupling agents. J Mech Behav Biomed Mater 17: 327-332.

24. Thompson JY, Stoner BR, Piascik JR, Smith R (2011) Adhesion/cementation to zirconia and other non-silicate ceramics: Where are we now? Dent Mater 27: 71-82.

25. Ozcan M, Allahbeickaraghi A, Dündar M (2012) Possible hazardous effects of hydrofluoric acid and recommendations for treatment approach: A review. Clin Oral Investig 26: 15-23.

26. Ozcan M, Dündar M, Çömlekoğlub ME (2012) Adhesion concepts in dentistry: tooth and material aspects. J Adhes Sci Technol 26: 2281-2661.

27. Magne P, Paranhos MP, Burnett LH Jr (2010) New Zirconia Primer improves bond strength of resin-based cements. Dent Mater 26: 345-352.

28. Dbradović-Djuricić K, Medić V, Dodić S, Gavrilov D, Antonijević D, et al. (2013) Dilemmas in zirconia bonding: A review. Srp Arh Celok Lek 141: 395-401.

29. Blatz MB, ChicheG, Holst S, Sadan A (2007) Influence of surface treatment and simulated aging on bond strengths of luting agents to zirconia. Quintessence Int 38: 745-753.

30. Palacios RP, Johnson GH, Phillips KM, Raigrodski AJ (2006) Retention of zirconium oxide ceramic crowns with three types of cements. J Prosthet Dent 96: 104-114. 